\title{
Apoptosis-induced mitochondrial dysfunction causes cytoplasmic lipid droplet formation
}

\author{
J Boren ${ }^{1,2}$ and KM Brindle, ${ }^{*, 2}$
}

A characteristic of apoptosis is the rapid accumulation of cytoplasmic lipid droplets, which are composed largely of neutral lipids. The proton signals from these lipids have been used for the non-invasive detection of cell death using magnetic resonance spectroscopy. We show here that despite an apoptosis-induced decrease in the levels and activities of enzymes involved in lipogenesis, which occurs downstream of p53 activation and inhibition of the mTOR signaling pathway, the increase in lipid accumulation is due to increased de novo lipid synthesis. This results from inhibition of mitochondrial fatty acid $\beta$-oxidation, which coupled with an increase in acyl-CoA synthetase activity, diverts fatty acids away from oxidation and into lipid synthesis. The inhibition of fatty acid oxidation can be explained by a rapid rise in mitochondrial membrane potential and an attendant increase in the levels of reactive oxygen species.

Cell Death and Differentiation (2012) 19, 1561-1570; doi:10.1038/cdd.2012.34; published online 30 March 2012

The responses of cells to stress are intimately connected to cellular metabolism. ${ }^{1}$ Central among the signaling pathways connecting the two are the phosphoinositide 3-kinase-AKTmTOR pathway, which promotes cell growth and survival by increasing energy production and protein synthesis, ${ }^{2}$ and the transcription factor $\mathrm{p} 53$, which under conditions of mild or transient stress, induces cell-cycle arrest and DNA repair before the cells re-enter a normal proliferative state when the stress has been resolved. In this situation p53 modulates the expression of several enzymes involved in metabolism, including a fructose-2,6-bisphosphatase, which diverts flux from glycolysis into the pentose phosphate pathway, ${ }^{3}$ increasing the production of NADPH, which acts, via reduced glutathione, to lower the raised levels of reactive oxygen species (ROS) and a mitochondrial glutaminase, which through increasing glutamate concentration increases the levels of glutathione. ${ }^{4}$ When the stress results in severe or irreparable damage, p53 produces a permanent inhibition of cell proliferation, through induction of apoptosis or senescence. ${ }^{5}$ Under these circumstances, p53 inhibits the AKT and mTOR signaling pathways by activating transcription of negative regulators such as PTEN and tuberous sclerosis complex 2 (TSC2). ${ }^{6}$

The re-direction of cellular metabolism during apoptosis is also controlled by AMP-activated protein kinase (AMPK). Increases in the levels of AMP in stressed cells stimulate AMPK activity, which increases the activities of those pathways that generate ATP while at the same time inhibiting those pathways that consume ATP, such as those involved in biosynthesis. ${ }^{7}$ Following induction of cell death, p53 induces the expression of Sestrins1 and 2, which possess antioxidant activity, and, through Sestrin 2, also activates AMPK, which forms a complex that activates TSC2 and inhibits the mTORC1 pathway ${ }^{8}$ (Figure 1). DNA damage induced by drugs, such as etoposide, also results in increased AMPK activity, via activation of ATM, as a mechanism to fulfill the energetic requirements of the DNA repair process. ${ }^{9}$

The metabolic changes resulting from the induction of cell death should result in an inhibition of lipid biosynthesis. Inhibition of the AKT and mTORC1 pathways results in a decrease in nuclear translocation of the sterol-regulatory element-binding protein 1 (SREBP-1), which regulates expression of lipogenic enzymes, ${ }^{10}$ (Figure 1) and activated AMPK has a direct effect on lipid synthesis by phosphorylating and inhibiting hydroxymethylglutaryl-CoA reductase and acetyl-CoA carboxylase (ACC1), ${ }^{11}$ therefore decreasing the levels of malonyl-CoA (Figure 1). Malonyl-CoA regulates the balance between lipogenesis and $\beta$-oxidation as it is both a substrate for fatty acid synthase (FASN) and an inhibitor of carnitine palmitoyltransferase I (CPT-1), which mediates uptake of fatty acids into the mitochondria. ${ }^{12}$

However, despite the expected inhibition of cellular lipid synthesis, an accumulation of cytoplasmic lipid droplets after induction of apoptosis has long been reported. ${ }^{13-15}$ As these give rise to a high-resolution ${ }^{1} \mathrm{H}$ nuclear magnetic resonance signal, ${ }^{14}$ which can be detected in vivo, they have been used as a non-invasive marker of tumor cell death post-treatment. ${ }^{13,16}$ However, why these droplets accumulate following the induction of apoptosis is not clear, although various suggestions have been made as to their origin, including redistribution of different lipid species between cellular compartments, ${ }^{17}$ increased neutral lipid synthesis during an

\footnotetext{
${ }^{1}$ Cancer Research UK Cambridge Research Institute, Li Ka Shing Centre, Cambridge, UK and ${ }^{2}$ Department of Biochemistry, University of Cambridge, Cambridge, UK *Corresponding author: KM Brindle, Cancer Research UK Cambridge Research Institute, Li Ka Shing Centre, Robinson Way, Cambridge CB2 ORE, UK.

Tel: + 441223333674 (440530); Fax: + 441223 766002; E-mail: kmb1001@cam.ac.uk

Keywords: apoptosis; lipid droplets; fatty acid oxidation; ROS; lipogenesis

Abbreviations: 7AAD, 7-aminoactinomycin D; ACC1, acetyl-CoA carboxylase; ACLY, ATP-citrate lyase; ACS, acyl-CoA synthetase; AMPK, AMP-activated protein kinase; AV, annexin V; CIDE, cell death-inducing DNA fragmentation factor 45-like effector; CPT-1, carnitine palmitoyltransferase I; DAG, diacylglycerides; DCFDA, carboxy-dichlorodihydrofluorescein diacetate; FAO, fatty acid oxidation; FASN, fatty acid synthase; FFA, free fatty acids; MEFs, mouse embryo fibroblasts; MRS, magnetic resonance spectroscopy; MTO, Mitotracker orange; ROS, reactive oxygen species; Sirt1, sirtuin 1; SREBP-1, sterol-regulatory element-binding protein 1; TAG, triacylglycerides; TMRM, tetramethylrhodamine methyl ester; TrC, Triacsin C; TSC2, tuberous sclerosis complex 2

Received 18.8.11; revised 07.2.12; accepted 23.2.12; Edited by S Kornbluth; published online 30.3.12
} 


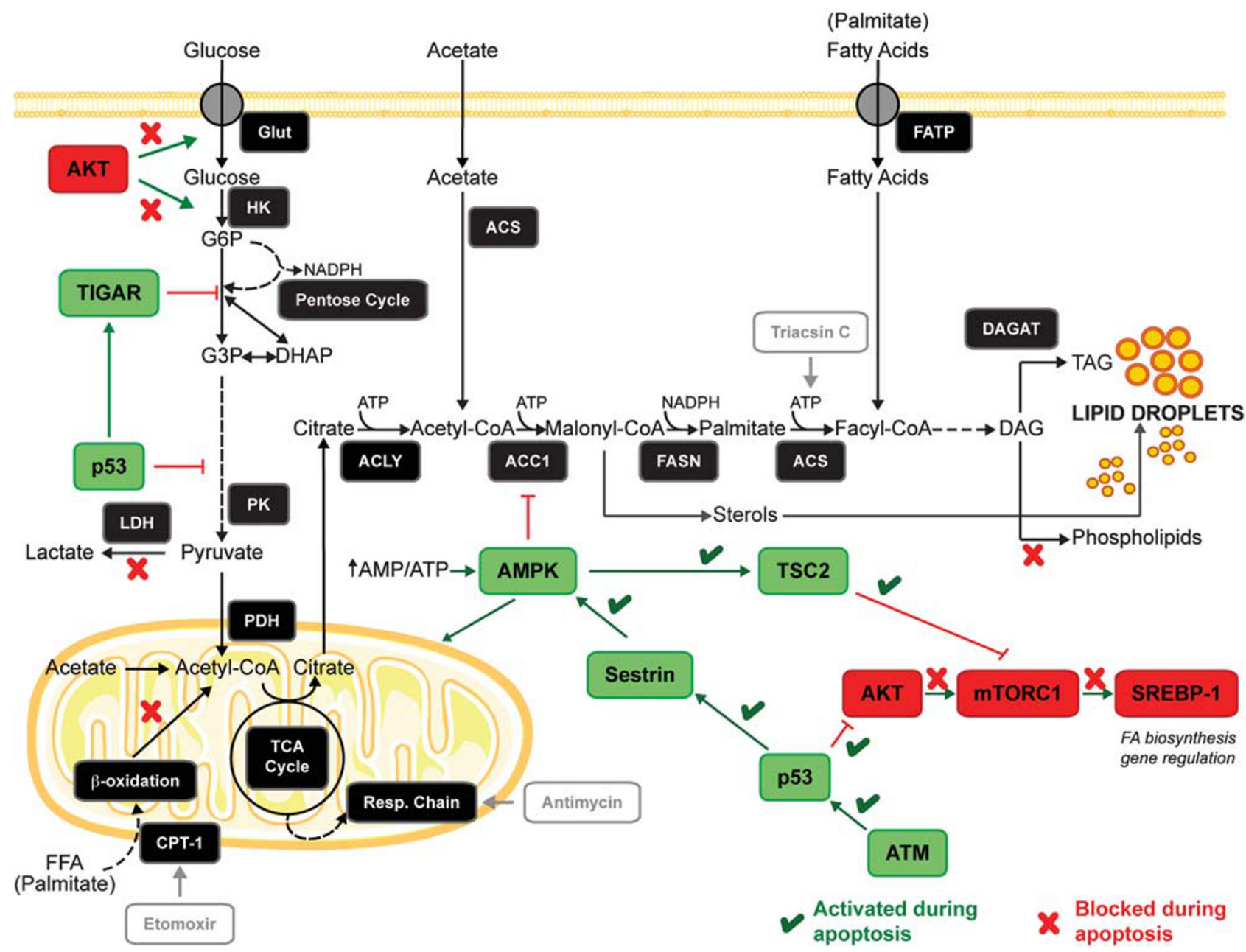

Figure 1 Apoptosis affects cell signaling pathways that control lipid synthesis and energy metabolism. The enzymes involved in de novo lipid synthesis are depicted as well as the signaling pathways that regulate them. Lipids are synthesized from citrate, which is transported into the cytosol following synthesis in the mitochondria by condensation of acetyl-CoA with oxaloacetate. Glucose is the principal origin of citrate carbon, although other metabolites can also be used as carbon donors. Lipid synthesis also requires NADPH, which originates from the pentose phosphate pathway and from the reaction catalyzed by malic enzyme. Pictures of the mitochondrion and cell membrane were obtained from Servier Medical Art (www.servier.com). ACC1, acetyl-CoA carboxylase; ACLY, ATP-citrate lyase; ACS, acyl-CoA synthetase; AMPK, AMPactivated kinase; ATM, ataxia-telangiectasia mutated; CPT-1, carnitine palmitoyltransferase 1; DAG, diacylglycerides; DAGAT, diacylglycerol acyltransferase; DHAP, dihydroxyacetone phosphate; FASN, fatty acid synthase; FATP, fatty acid transport protein; FFA, free fatty acids; G3P, glyceraldehyde 3-phosphate; G6P, glucose 6phosphate; Glut, glucose transporter; HK, hexokinase; LDH, lactate dehydrogenase; PDH, pyruvate dehydrogenase; PK, pyruvate kinase; SREBP-1, sterol-receptor element binding protein; TAG, triacylglycerides; TIGAR, Tp53-induced glycolysis and apoptosis regulator; TSC2, tuberous sclerosis complex 2

active phase of apoptosis, ${ }^{18}$ increased lipid content caused by organelle degradation or autophagy, ${ }^{19}$ or enhanced phospholipase A2 activity. ${ }^{16}$

Lipid droplets are dynamic organelles consisting of a central core of neutral lipids, mainly triacylglycerides (TAG) and cholesterol esters, surrounded by a monolayer of phospholipids that contains several proteins associated with lipid metabolism and membrane trafficking. ${ }^{20}$ Lipid droplets have been associated with several processes, including energy regulation, fatty acid storage, control of lipid signaling molecules and mediation of lipid toxicity. ${ }^{21}$ They also interact with other structures inside the cell, such as mitochondria and the endoplasmic reticulum (ER), ${ }^{20}$ which are intimately involved in the progression of the apoptotic program.
We show here that the accumulation of cytoplasmic lipid droplets during apoptosis can be explained by an early inhibition of mitochondrial fatty acid oxidation (FAO) and that, despite the decrease in the cell's capacity for lipid synthesis, which occurs downstream of activation of $p 53$ and inhibition of the mTOR signaling pathway, this results in increased TAG synthesis and lipid droplet formation.

\section{Results}

Induction of apoptosis leads to an early increase in cytoplasmic lipid droplet formation and mitochondrial membrane potential. Etoposide-induced apoptosis of murine lymphoma cells (EL4) resulted in an increase in the 
number of cytoplasmic lipid droplets (Figure 2a). This increase was observed as early as $2 \mathrm{~h}$ after drug treatment when the levels of early apoptosis and late apoptosis/ necrosis, determined by annexin $\mathrm{V}$ (AV) and 7aminoactinomycin $\mathrm{D}$ (7AAD) staining respectively, were similar to those in untreated cells (Figures $2 b$ and $c$ ). The increase in lipid staining was evident in etoposide-treated cells that appeared to be viable (AV and 7AAD negative), indicating that lipid droplet formation is an early event following induction of apoptosis in these cells. This increase in lipid droplet number following the induction of apoptosis, which has been reported in previous studies, ${ }^{18,22}$ was also observed in other cell lines that had been treated with different apoptosis-inducing agents, including the prostate cancer cell lines C4-2b and DU145 and the human colon adenocarcinoma, HCT116 (Supplementary Figure S1). This phenomenon is not specific to tumor cells as we also observed it in mouse embryo fibroblasts (MEFs) treated with etoposide (Supplementary Figure S2).

The effect of apoptosis induction on mitochondrial function was analyzed with Mitotracker orange (MTO), which stains functionally active mitochondria, accumulating in a membrane a

$2 \mathrm{~h}$

$8 \mathrm{~h}$

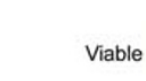

Early Apoptotic

Necrotic

$16 \mathrm{~h}$
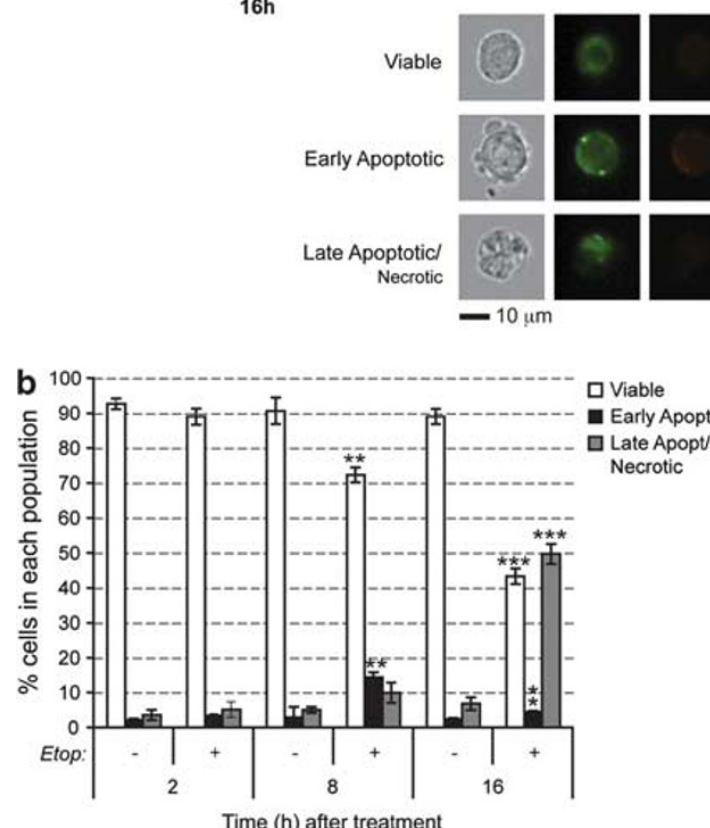

CONTROL

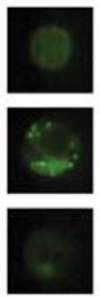

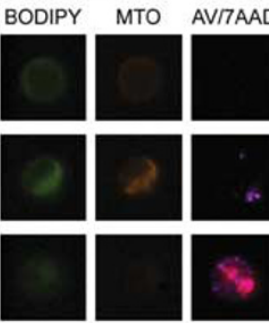
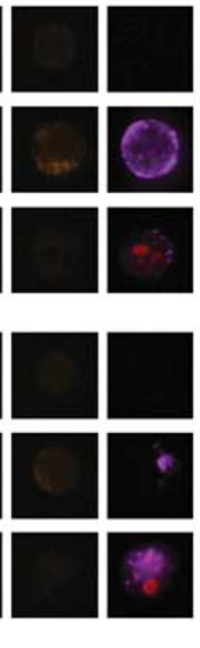

C

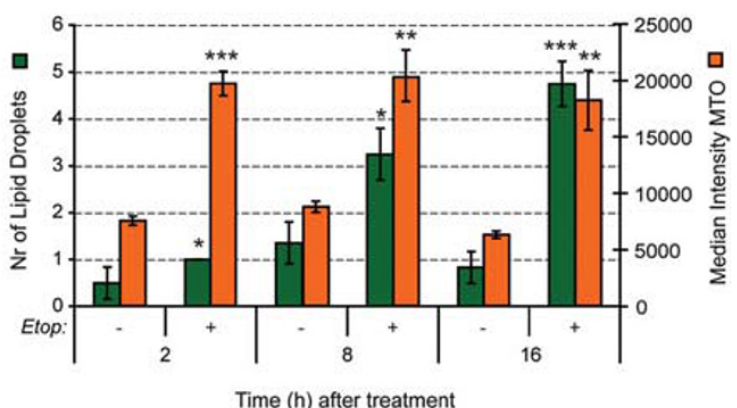

Figure 2 Apoptosis induction increases lipid droplet content and mitochondrial membrane potential in EL4 cells. (a) Representative images obtained with an ImageStream imaging flow cytometer. Cells were treated with $15 \mu \mathrm{M}$ etoposide for 2,8 or $16 \mathrm{~h}$, after which they were stained with Bodipy $496 / 503$ (stains neutral lipids), MTO (stains mitochondria in a membrane potential-dependent manner), 7AAD (a DNA stain indicating late apoptosis or necrosis) and AV-AF647 (an indicator of early apoptosis). (b) Fraction of viable, early apoptotic and late apoptotic/necrotic cells. Cell populations were gated according to their AV/7AAD staining. Results are expressed as mean \pm S.E.M. and indicate the average values of at least four different experiments with 10000 cells analyzed per sample. (c) Quantification of lipid droplet number, which was assessed as described in Materials and Methods, and MTO intensity as a measure of mitochondrial membrane potential (expressed in arbitrary units), after induction of cell death. Results are expressed as mean \pm S.E.M., $n=4 .{ }^{\star} P<0.05,{ }^{\star *} P<0.01,{ }^{\star * *} P<0.001$ 
potential-dependent manner. ${ }^{23}$ Increased staining intensity in drug-treated cells indicated an increase in mitochondrial membrane potential (Figures $2 a$ and $c$ ), which was already apparent by $2 \mathrm{~h}$ after drug treatment in the viable and early apoptotic cell populations. To confirm the increase in mitochondrial membrane potential, cells were also stained with tetramethylrhodamine methyl ester (TMRM), which is a specific indicator of membrane potential. ${ }^{24}$ There was a fivefold increase in dye intensity by $2 \mathrm{~h}$ after etoposide treatment $(507 \pm 19 \%$ in drug-treated cells versus $100 \pm 1.5 \%$ in control cells; $n=3, P<0.00001$; mean \pm S.E.M.).

Increased lipid droplet formation correlates with increased lipogenesis. To investigate the origin of lipid droplet accumulation following induction of apoptosis in EL4 cells, we analyzed de novo lipid synthesis by measuring the incorporation of $\left[1,2-{ }^{14} \mathrm{C}_{2}\right]$ acetate into cellular lipids. The labeled acetate was added to the cell suspension $1 \mathrm{~h}$ before cell harvest and the incorporation of ${ }^{14} \mathrm{C}$ label into neutral and polar lipids (Figures $3 a$ and b) was determined. As early as $2 \mathrm{~h}$ after drug treatment, there was a threefold increase in acetate incorporation into triacylglycerol (TAG) relative to untreated control cells $(P<0.03)$, and this continued to rise until $8 \mathrm{~h}$ after treatment, whereupon there was a subsequent decrease (Figure 3c). The decrease coincided with a significant loss of cell viability, which correlated with increased levels of cleaved caspase 3 (Figures $3 g$ and $h$ ). By 14 and $16 \mathrm{~h}$ after drug treatment, acetate incorporation into TAG was less than in untreated control cells (Figure $3 c$ ). Next, we investigated incorporation of fatty acids into TAG by incubating the cells with ${ }^{14} \mathrm{C}$-palmitate (Figures $3 \mathrm{~d}$ and e). There was no significant increase in incorporation compared with untreated control cells until $4 \mathrm{~h}$ after drug treatment, when this increased incorporation continued to rise until peaking at $12 \mathrm{~h}$ and was still higher than in untreated control cells at 14 and $16 \mathrm{~h}$ (Figure $3 \mathrm{f}$ ). Both $\left[1,2-{ }^{14} \mathrm{C}_{2}\right]$ acetate and ${ }^{14} \mathrm{C}$-palmitate showed a general decrease in incorporation into polar lipids following drug treatment (Figures $3 b$ and e), as observed previously. ${ }^{25}$ MEFs also showed increased lipid synthesis at $24 \mathrm{~h}$ after treatment with etoposide (Supplementary Figure S2B).

Cell signaling pathways affected by the induction of apoptosis can inhibit lipogenesis. Etoposide-induced apoptosis in EL4 cells produced the expected increase in p53 protein (Figure 4a) and in the expression of the p53responsive genes, $p 21$ and Sestrin 2 (Figures 1 and $4 b$ ). There was an increase in AMPK phosphorylation, which coincided with increased expression of Sestrin 2, and a decrease in phosphorylated p70-S6K (Figure 4a), consistent with inhibition of the activity of the mTORC1 complex. There appeared to be no significant change in Akt serine 473 phosphorylation, although there was a decrease in the level of the total protein at later time points (Figure 4a). The increase in AMPK phosphorylation and activity and the phosphorylation and consequent inhibition of mTORC1 are expected to decrease the expression of the lipogenic enzymes, ${ }^{10}$ and also to inhibit lipogenesis more acutely through phosphorylation and inhibition of $\mathrm{ACC}^{7}{ }^{7}$ (Figure 1).
Induction of apoptosis affects the expression and activity of lipogenic enzymes. ATP-citrate lyase (ACLY), the first enzyme of the de novo lipid synthesis pathway (Figure 1), which catalyses the conversion of citrate into acetyl-CoA, showed no significant change in gene expression (Figure 4c) nor in the level of the active phosphorylated protein ( $p-A C L Y$ ) (Figure 4d) following etoposide treatment. The next enzyme in the pathway, $A C C 1$, showed increased phosphorylation ( $p-A C C 1)$ by $2 h$ after drug treatment (Figure 4d), consistent with the observed phosphorylation and activation of AMPK (Figure 4a). This phosphorylation-dependent inhibition of the enzyme was compounded by decreased expression of the ACC1 gene (Figure 4c) and decreased enzyme protein at later time points (Figure 4d). FASN also showed significantly decreased gene expression by $4 \mathrm{~h}$ after drug treatment and this was also reflected in a decrease in enzyme protein at later time points. The decrease in the levels of FASN could explain the decrease in acetate incorporation between 14 and $16 \mathrm{~h}$ after drug treatment (Figure $3 \mathrm{c}$ ). The levels of acylCoA synthetase (ACS), which catalyzes ATP-dependent activation of free fatty acids (FFA) into fatty acyl-CoAs (Figure 1), increased continually following drug treatment, mirroring the decline in the levels of FASN (Figure 4d). The expression of $A C S$ is activated by increased levels of FFA and by lipid droplets. ${ }^{26}$ Accordingly, the observed increase in ACS protein (Figure 4d) paralleled the increase in lipid droplet number (Figure 2c) and could explain the sustained incorporation of ${ }^{14} \mathrm{C}$-palmitate into TAG at the later time points after drug treatment (Figure 3f). Furthermore, the activity of ACS is enhanced by deacetylation by sirtuin 1 (Sirt1) in response to a decrease in NAD ${ }^{+}$concentration. ${ }^{27}$ The observed $\operatorname{NAD}(\mathrm{H})$ depletion in EL4 cells treated with etoposide, which has been shown to be due to poly(ADP-ribose)polymerase activation, ${ }^{28}$ correlated with increased Sirt1 protein levels (Supplementary Figure S3A), indicating that the activity of the ACS enzyme could also be enhanced at later time points after drug treatment.

To confirm the importance of ACS and de novo TAG synthesis for lipid droplet formation, cells were treated with Triacsin C (TrC), which is a specific inhibitor of the enzyme. Despite enhancing the induction of apoptosis by etoposide (Supplementary Figure S3B), the drug inhibited lipid droplet formation (Supplementary Figure S3C), decreased the incorporation of ${ }^{14} \mathrm{C}$-acetate into TAG and increased ${ }^{14} \mathrm{C}$ incorporation into FFA (Supplementary Figures S3D and S3E). However, the increase in ACS content was not observed until $6 \mathrm{~h}$ after etoposide treatment and therefore cannot explain the earlier increase in lipid droplet content (Figure 2c) and TAG synthesis from ${ }^{14} \mathrm{C}$-acetate (Figure $3 \mathrm{c}$ ), which were already apparent at $2 \mathrm{~h}$ after drug treatment, and the increased TAG synthesis from ${ }^{14} \mathrm{C}$ palmitate, which was already observed at $4 \mathrm{~h}$ after drug treatment (Figure 3f).

Induction of apoptosis increases formation of ROS and decreases lipid $\boldsymbol{\beta}$-oxidation. The delayed changes in ACS activity suggest that there must be other factors contributing to the early increases in TAG synthesis and subsequent lipid droplet formation following the induction of apoptosis. The 
a

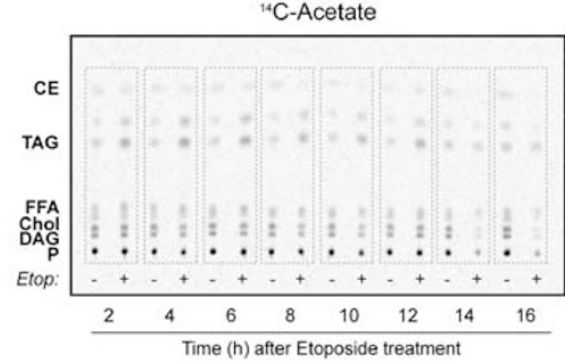

b

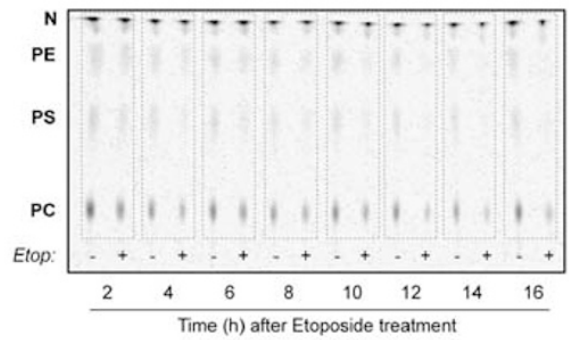

C

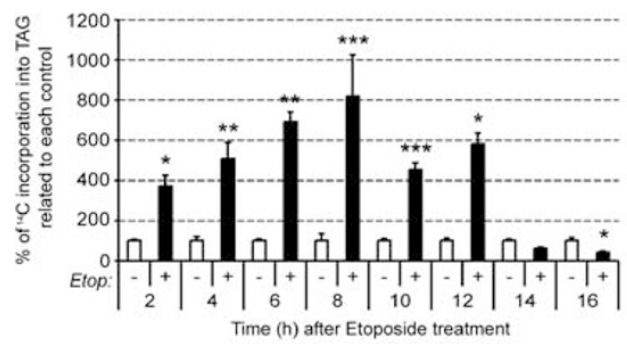

g

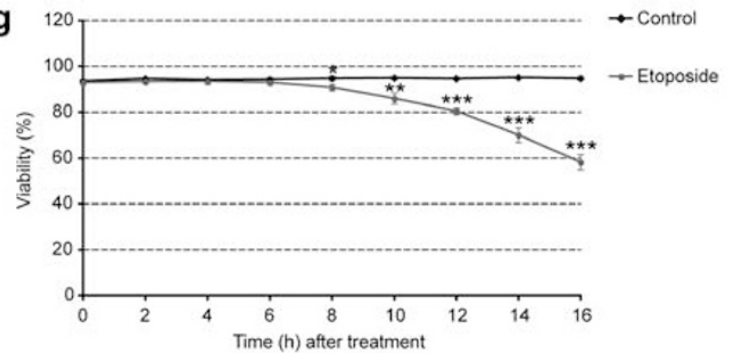

d ${ }^{\text {"CC-Palmitate }}$
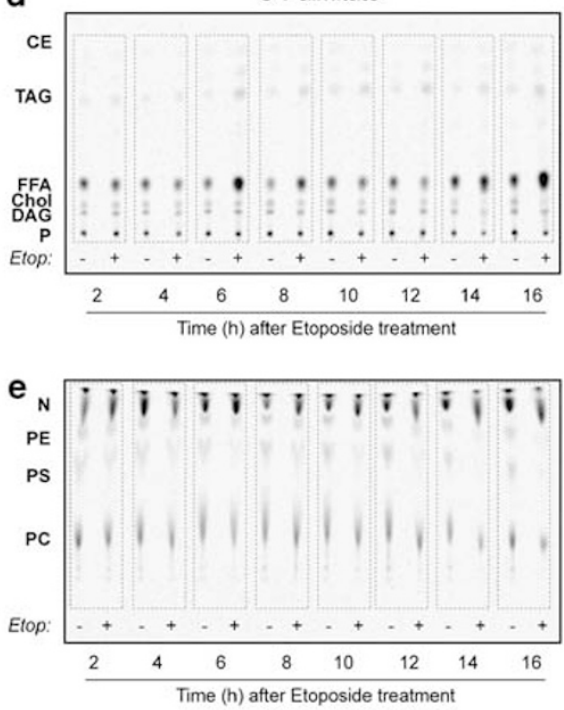

f

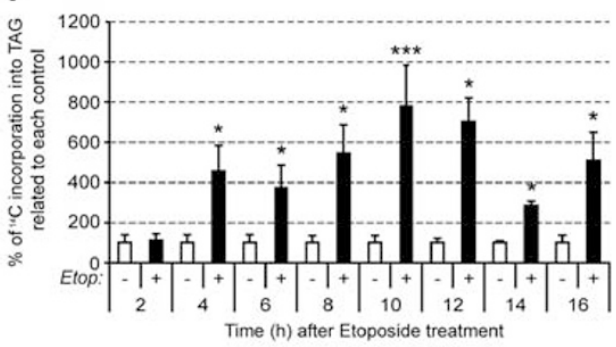

h

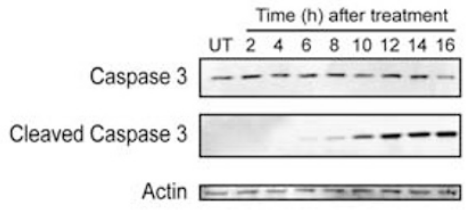

Figure 3 Etoposide-induced apoptosis enhances lipogenesis. (a) Cells were incubated with ${ }^{14} \mathrm{C}$-acetate for $1 \mathrm{~h}$ before harvesting at the indicated times after etoposide treatment. Lipids were extracted and the extract volume normalized for cell number before the lipids were separated on a thin layer chromatography (TLC) plate. A representative autoradiograph indicating ${ }^{14} \mathrm{C}$-acetate incorporation into the different neutral lipid species is shown. (b) Representative autoradiograph of the polar lipid fraction on TLC plates showing ${ }^{14} \mathrm{C}$-acetate incorporation. (c) ${ }^{14} \mathrm{C}$-acetate incorporation into TAG determined by densitometric analysis of the autoradiographs. The values represent the percentage incorporation relative to control (mean \pm S.D., $n=9$ ). (d) Representative autoradiograph of ${ }^{14} \mathrm{C}$-palmitate incorporation into the neutral lipid fraction on TLC plates. The cells were incubated with ${ }^{14} \mathrm{C}$-palmitate for $1 \mathrm{~h}$ before harvesting at the indicated times after etoposide treatment. The volume of the lipid extraction buffer was normalized to cell number. (e) Representative autoradiograph of the polar lipid fraction on TLC plates from cells incubated with ${ }^{14} \mathrm{C}$-palmitate. (f) ${ }^{14} \mathrm{C}$-palmitate incorporation into TAG determined by densitometry. The values represent the percentage incorporation relative to control (mean \pm S.D., $n=9$ ). (g) Cell viability after etoposide treatment measured by Trypan blue dye exclusion assay. Results are expressed as mean \pm S.D. $(n=9)$. (h) Representative western blot showing the effect of etoposide treatment on caspase 3 cleavage $(n=3) .{ }^{\star} P<0.05,{ }^{\star \star} P<0.01,{ }^{* \star \star} P<0.001$. CE, cholesterol esters; Chol, cholesterol; DAG, diacylglycerides; Etop, etoposide; FFA, free fatty acids; $N$, neutral lipids; P, polar lipids; PC, phosphatidylcholine; PE, phosphatidylethanolamine; PS, phosphatidylserine; TAG, triacylglycerides

effect of inducing apoptosis on FAO was determined by incubating EL4 cells with ${ }^{14} \mathrm{C}$-oleate or ${ }^{14} \mathrm{C}$-palmitate and measuring ${ }^{14} \mathrm{CO}_{2}$ production. Etoposide treatment resulted in a progressive decrease in oleate oxidation, which was already evident by $2 \mathrm{~h}$ after drug treatment, when it was $20 \%$ lower than in control cells. Palmitate oxidation showed a similar trend to oleate. A similar decrease in oleate oxidation was also observed in etoposide-treated MEFs, again demonstrating that the metabolic effects observed here were not specific to tumor cells (Supplementary Figure S2B). Glucose oxidation in EL4 cells, however, only decreased after $6 \mathrm{~h}$ of drug treatment, reaching a $20 \%$ decrease by $10 \mathrm{~h}$ (Figure $5 \mathrm{a}$ ). The decrease in glucose oxidation paralleled caspase 3 activation (Figure $3 \mathrm{~h}$ ), 
a

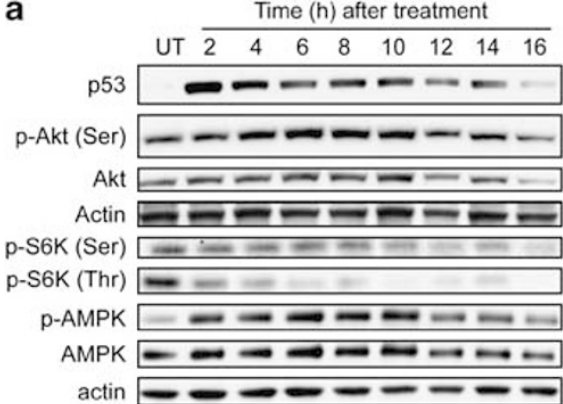

C

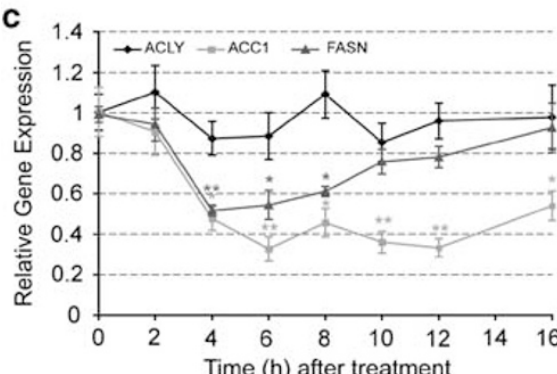

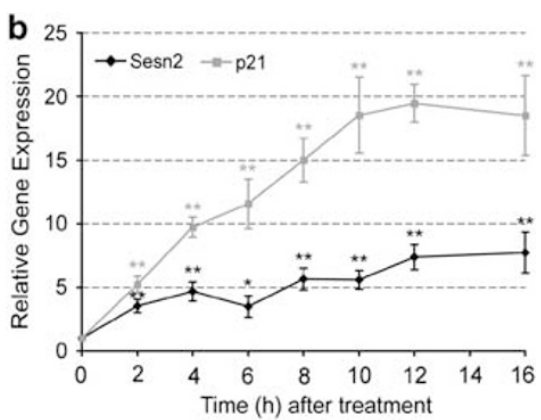

d

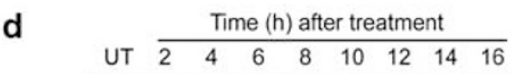

p-ACLY $-\ldots-\cdots-\cdots$
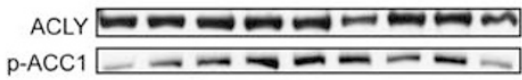

$\mathrm{ACC} 1=-\cdots-\cdots-\cdots$

FASN $\approx-\infty-\infty-\infty N-\infty$

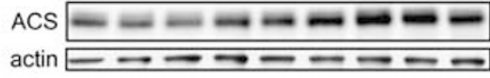

Figure 4 Apoptosis modulates signaling pathways that alter gene expression, protein levels and phosphorylation status of lipogenic enzymes. EL4 cells were treated with $15 \mu \mathrm{M}$ etoposide for up to $16 \mathrm{~h}$ and protein samples were obtained every $2 \mathrm{~h}$. (a) Representative western blots showing of the effect of apoptosis induction on the levels of p53, Akt, p-Akt (Ser473), pS6K (Ser371), pS6K (Thr389), AMPK and p-AMPK (Thr172). Actin was used as an internal control for protein loading. (b) Expression levels of Sestrin 2 $(\triangle)$ and p21 $(\square)$ obtained by quantitative polymerase chain reaction (PCR). Results are expressed in relation to their initial levels (untreated controls). Actin expression levels were used to normalize the results (mean \pm S.E.M.; ${ }^{*} P<0.01,{ }^{* \star} P<0.001, n=3$ ). (c) Expression levels of $A C L Y(\triangle), A C C 1(\square)$ and $F A S N(\triangle)$ obtained by quantitative PCR. Results were normalized to the actin levels in each sample and expressed relative to the untreated control (mean \pm S.E.M.; ${ }^{*} P<0.01,{ }^{* \star} P<0.001, n=3$ ). (d) Western blot analysis of the levels of ACLY, p-ACLY (Ser454), ACC1, p-ACC1 (Ser79), FASN and ACS. Actin was used as an internal protein loading control. $A$ representative sample is shown for each protein

suggesting that the decrease in glucose oxidation might be the result of cytochrome $c$ release from the mitochondria, which through formation of the apoptosome could be responsible for the observed caspase 3 cleavage. These results suggest that increased TAG synthesis and lipid droplet accumulation following etoposide treatment could be due to reduced mitochondrial FAO. This apparent inverse correlation between TAG synthesis and lipid droplet formation on the one hand and mitochondrial lipid oxidation on the other was further tested by treating cells with etomoxir, a CPT-1 inhibitor that blocks mitochondrial fatty acid uptake. ${ }^{29}$ Treatment of cells with etomoxir for $2 \mathrm{~h}$ had no effect on cell viability but resulted in a $20 \%$ decrease in oleate oxidation, whereas oleate incorporation into lipids was increased by $50 \%$, indicating a redirection of fatty acids from oxidation into biosynthesis (Figures $5 b$ and $c$ ). There was no evidence for involvement of CIDE (cell death-inducing DNA fragmentation factor 45-like effector) proteins $^{30}$ in these changes in lipid metabolism (Supplementary Figure S4).

The recently demonstrated ROS-dependent inhibition of mitochondrial $\mathrm{FAO}^{31}$ could provide an explanation for the early decrease in FAO following the induction of apoptosis with etoposide. Consistent with this proposal, we observed that when mitochondrial ROS production was induced by treating EL4 cells for $2 \mathrm{~h}$ with antimycin, an inhibitor of complex III that increases mitochondrial $\mathrm{H}_{2} \mathrm{O}_{2}$ formation, ${ }^{32}$ there was a $40 \%$ decrease in oleate oxidation (Figure $5 b$ ) and an accompanying increase in ${ }^{14} \mathrm{C}$-oleate incorporation into TAG (Figure 5c).

The effect of inducing apoptosis on cellular ROS production was examined by staining cells with carboxy-dichlorodihydrofluorescein diacetate (DCFDA) (Figure 6a). Etoposide treatment resulted in a rapid and marked increase in ROS levels, which were four times the levels observed in control cells by $2 \mathrm{~h}$ after drug treatment. This increase in ROS levels paralleled the marked increase in mitochondrial membrane potential determined using MTO (Figures $2 \mathrm{a}$ and $\mathrm{c}$ ) and TMRM. However, while tocopherol appeared to reduce the levels of ROS in etoposide-treated cells to those observed in control cells (Figure $6 b$ ), it neither restored oleate oxidation to control levels (Figure 6c) nor decreased oleate incorporation into TAG (Figure 6d). Similar results were obtained with other cytosolic antioxidants (data not shown), suggesting, as indicated by the experiments with antimycin, that it is ROS levels in the mitochondria, and not in the cytosol, that account for the observed inhibition of lipid $\beta$-oxidation. To prove that mitochondrial ROS were responsible for inhibition of lipid $\beta$-oxidation, we treated cells with mitoubiquinone (MitoQ), which is a mitochondrially targeted antioxidant that blocks mitochondrial oxidative damage. ${ }^{33}$ The antioxidant ubiquinone moiety is targeted to the mitochondria by covalent attachment of a lipophilic triphenylphosphonium cation via an aliphatic carbon chain. As a control for the effects of the triphenylphosphonium ion on mitochondrial function, we used MitoQ lacking the ubiquinone moiety (DecylTPP). Cells 


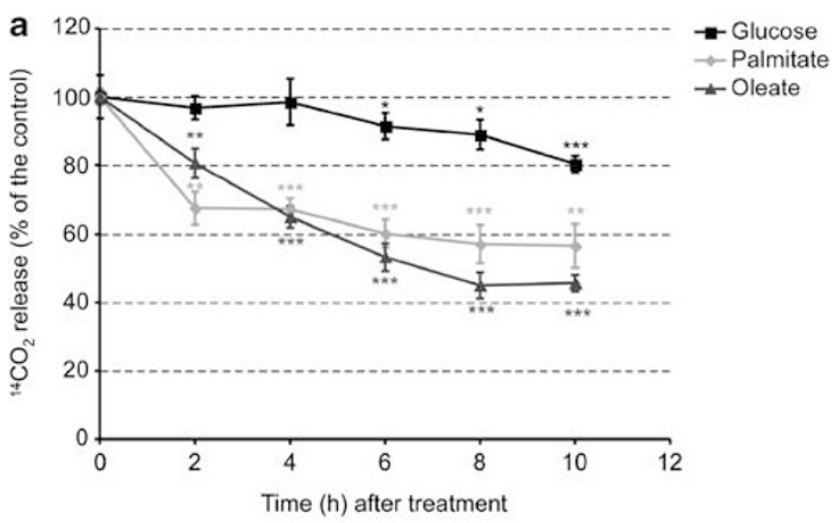

b

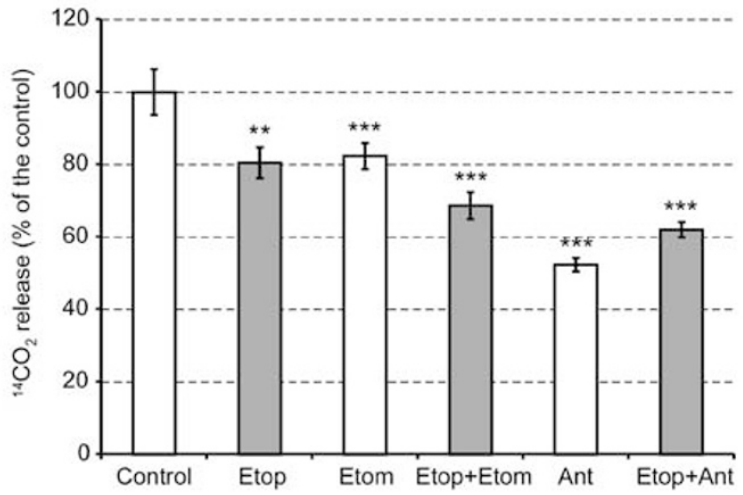

C

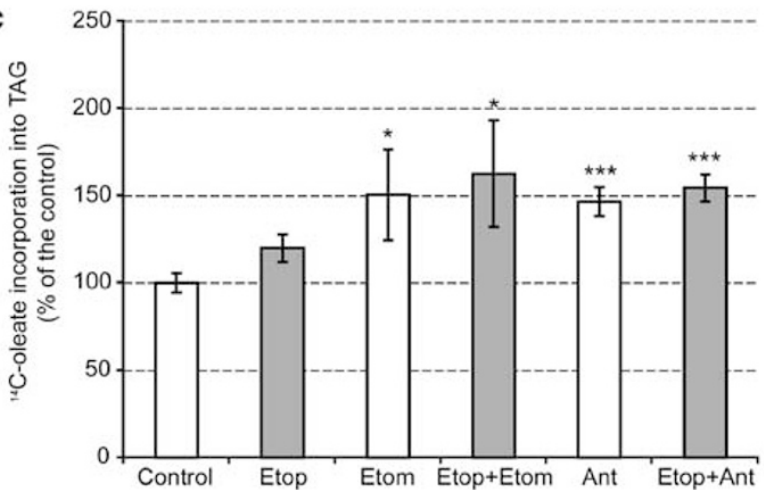

Figure 5 Apoptosis decreases mitochondrial fatty acid $\beta$-oxidation. (a) EL4 cells were treated with $15 \mu \mathrm{M}$ etoposide for the indicated times and $1 \mathrm{~h}$ before harvesting, $1 \mu \mathrm{Ci} / \mathrm{ml}\left[1{ }^{14} \mathrm{C}\right]$ palmitate, $0.5 \mu \mathrm{Ci} / \mathrm{ml}\left[1-{ }^{14} \mathrm{C}\right]$ oleate or $2 \mu \mathrm{Ci} / \mathrm{ml} \mathrm{D}$ [U- ${ }^{14} \mathrm{C}$ ]glucose were added to the culture medium. Counts in trapped ${ }^{14} \mathrm{CO}_{2}$ were normalized to the total cell number and expressed as a percentage of the untreated control cells (mean \pm S.E.M., $n=9$ ). (b) Oleate oxidation was measured in cells treated for $2 \mathrm{~h}$ with different combinations of $15 \mu \mathrm{M}$ etoposide (Etop), $100 \mu \mathrm{M}$ etomoxir (Etom) and/or $10 \mu \mathrm{M}$ antimycin (Ant). Neither etomoxir nor antimycin treatment affected cell viability (mean \pm S.E.M., $n=6$ ). (c) Oleate incorporation into TAG after treatment as in (b), assessed by densitometric analysis of autoradiographs of thin layer chromatography (TLC) plates (mean \pm S.E.M., $n=6) .{ }^{\star} P<0.05,{ }^{* *} P<0.01,{ }^{* \star *} P<0.001$

treated with etoposide and DecylTPP showed the same decrease in lipid oxidation as cells treated with etoposide alone or etoposide plus tocopherol (Figure 6c). However, in cells treated with etoposide and MitoQ lipid oxidation increased to above control levels and there was a corresponding decrease in lipid synthesis (Figure 6d).

\section{Discussion}

Increased lipid droplet formation following the induction of cell death has been widely observed ${ }^{16-19}$ and has formed the basis of a non-invasive magnetic resonance imaging technique to detect tumor cell death post-treatment. ${ }^{13}$ However, the mechanisms responsible for the accumulation of these droplets in dying cells are unclear.

We have shown here, in different cell types, that the induction of cell death resulted in the rapid accumulation of cytoplasmic lipid droplets. In EL4 murine lymphoma cells, this increased droplet accumulation, which was already evident by $2 \mathrm{~h}$ after drug treatment, was accompanied by an increase in mitochondrial membrane potential, an increase in ROS production, an increase in de novo neutral lipid synthesis and a decrease in lipid $\beta$-oxidation. The increase in lipid synthesis occurred despite the expected overall downregulation or inhibition of enzymes involved in lipogenesis, downstream of p53 and AMPK activation. There was a decrease in FASN mRNA by $4 \mathrm{~h}$ and a decrease in protein by $10 \mathrm{~h}$ and there was AMPKdependent phosphorylation and inhibition of ACC 1 by $2 \mathrm{~h}$ and $\mathrm{a}$ decrease in its expression by $4 \mathrm{~h}$. There was, however, an increase in the levels of ACS protein at later time points (after $6 \mathrm{~h}$ ), when the activity of the enzyme is expected to be increased by deacetylation by Sirt 1 in response to the decrease in $\mathrm{NAD}^{+}$concentration. The incorporation of fatty acids into diacylglycerides (DAG) and TAG will be enhanced by the increase in ACS activity and indeed we observed sustained incorporation of ${ }^{14} \mathrm{C}$ label from palmitate into TAG at a time when incorporation of label from acetate, which relies on the activities of ACC1 and FASN, was declining.

Thus, we propose that lipid droplet accumulation following the induction of apoptosis is due to de novo neutral lipid synthesis as a result of inhibition of mitochondrial fatty acid $\beta$-oxidation and re-direction of fatty acids away from oxidation and into lipid synthesis. That inhibition of lipid oxidation could result in such a reciprocal upregulation of lipid synthesis was demonstrated here by treating cells with the CPT-1 inhibitor etomoxir, which inhibited oleate oxidation and increased its incorporation into TAG, and by inhibiting complex III in the mitochondrial respiratory chain with antimycin, which had a similar effect. Treatment of cells with compounds that result in mitochondrial toxicity has been shown previously to result in lipid droplet formation, although this was attributed to lysosomal processing of lipids from damaged mitochondria rather than inhibition of $\beta$-oxidation. ${ }^{19}$

The demonstration that increases in ROS levels in mammary epithelial cells, caused by matrix detachment, resulted in inhibition of $\mathrm{FAO}^{31}$ suggested a potential mechanism whereby apoptosis induction could lead to inhibition of lipid oxidation and led us to investigate whether the increased ROS levels observed here could be responsible for the observed decrease in $\beta$-oxidation. Consistent with this proposal was the observation that inhibition of the respiratory chain with antimycin, which results in the generation of intramitochondrial $\mathrm{H}_{2} \mathrm{O}_{2}$, ${ }^{32}$ both inhibited oleate oxidation and increased its incorporation into lipid. However, while $\alpha$-tocopherol treatment appeared to prevent completely the etoposide-induced increase in cellular ROS, it neither restored oleate oxidation nor decreased oleate incorporation 

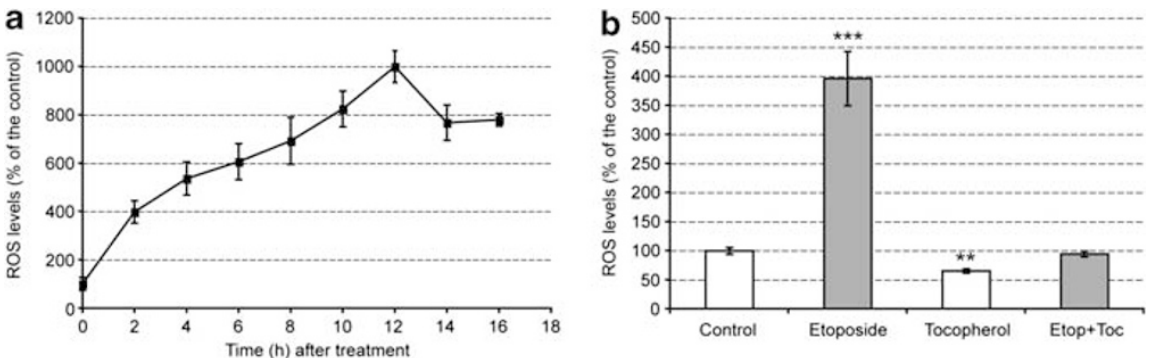

C

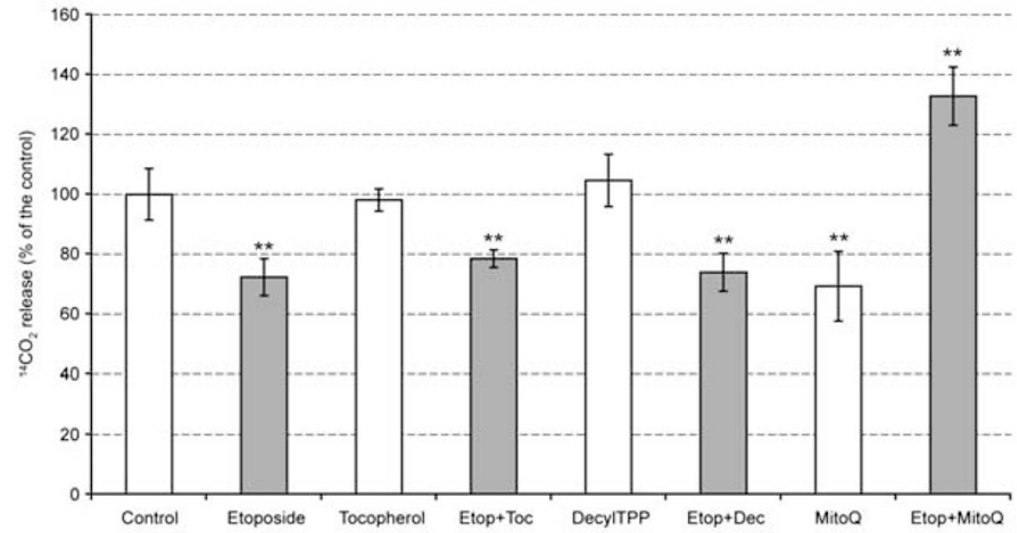

d

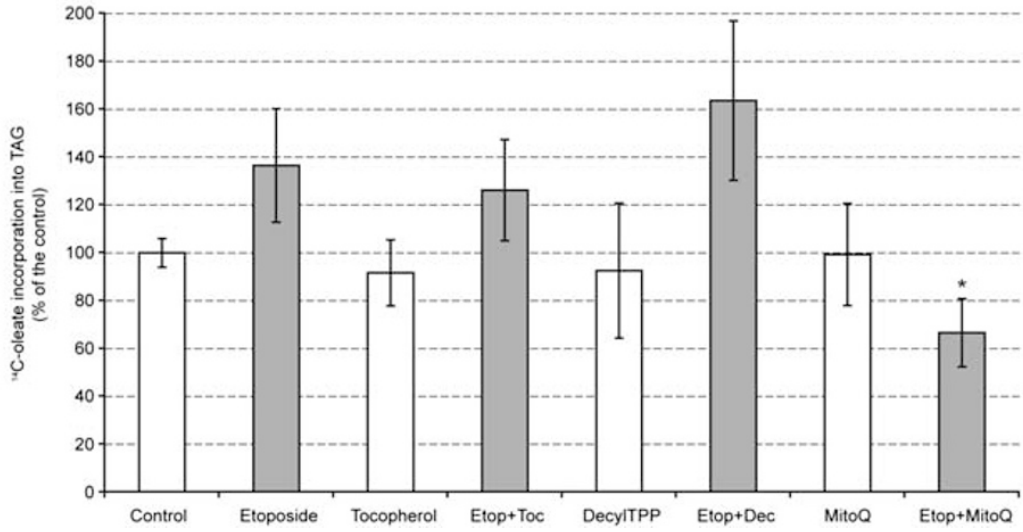

Figure 6 Apoptosis induction increases the levels of ROS in the cell. (a) ROS levels were measured by flow cytometry after staining the cells with carboxy- $\mathrm{H}_{2} \mathrm{DCFDA}$ and are expressed as the percentage increase in median fluorescence compared to untreated controls (mean \pm S.E.M.; $P<0.005$ in all points, $n=6$ ). (b) Cells were pretreated for $1 \mathrm{~h}$ with $9.5 \mu \mathrm{g} / \mathrm{ml}$ tocopherol (Toc), after which etoposide (Etop) was added into the cell medium for a further $2 \mathrm{~h}$ and then the cells were harvested. Results were expressed as the percentage of the values in control cells (mean \pm S.E.M., $n=3$ ). (c) ${ }^{14} \mathrm{C}$-oleate was added to cells $1 \mathrm{~h}$ before harvest to assess $\beta$-oxidation. Results are expressed relative to the level of oxidation in control cells as the mean \pm S.E.M., $n=6$. (d) The lipid fraction was obtained from cells treated as in (c) and densitometric analysis of autoradiographs of thin layer chromatography (TLC) plates was used to assess oleate incorporation into TAG, as described in Materials and methods. In (c) and (d), $1 \mu \mathrm{M}$ MitoQ, $1 \mu \mathrm{M}$ DecylTPP (Dec) or $9.5 \mu \mathrm{g} / \mathrm{ml}$ tocopherol were added to the cells $1 \mathrm{~h}$ before adding $15 \mu \mathrm{M}$ etoposide and the cells were then incubated for a further $2 \mathrm{~h}$. Dec was used to control for the effect of the triphenylphosphonium ion on mitochondrial function. Results are expressed as percentage of incorporation relative to untreated controls (mean \pm S.E.M., $n=6$ ). Significantly different from control at: ${ }^{*} P<0.05,{ }^{\star *} P<0.01,{ }^{* \star \star} P<0.001$

into TAG; similar results were obtained with other antioxidants. However, when etoposide was combined with a mitochondrially targeted antioxidant, MitoQ, there was recovery of lipid $\beta$-oxidation, which was accompanied by a decrease in fatty acid incorporation into TAG. A similarly targeted version of $\alpha$-tocopherol has been shown to be much more effective at protecting mitochondrial function from oxidative damage than $\alpha$-tocopherol alone. ${ }^{34}$ These results corroborate the relationship between mitochondrial ROS production and inhibition of lipid $\beta$-oxidation and confirm the reciprocal relationship between lipid oxidation and its incorporation into neutral lipid droplets. These results are in agreement with previous studies showing that $\mathrm{H}_{2} \mathrm{O}_{2}$ inhibits fatty acid $\beta$-oxidation ${ }^{35}$ and that many of the proteins in heart mitochondria, whose thiol redox state was affected by generation of intramitochondrial ROS, either at complex I by reverse electron transfer or at complex III by inhibition with antimycin, were those involved in $\mathrm{FAO} .^{36}$

Thus, the model that emerges from our results is that induction of apoptosis leads to a rapid rise in mitochondrial membrane potential and the generation of intramitochondrial ROS, which includes $\mathrm{H}_{2} \mathrm{O}_{2}$. The mitochondrial $\mathrm{H}_{2} \mathrm{O}_{2}$ reacts reversibly with thiol groups in the enzymes involved in fatty acid $\beta$-oxidation and inhibits them. The inhibition of 
$\beta$-oxidation, when combined with the increase in ACS activity, diverts fatty acids into TAG synthesis and the formation of lipid droplets.

Lipid droplets could have several functions in the apoptotic and pre-apoptotic cell. In damaged cells, where there is a ROS-dependent increase in mitochondrial membrane potential and inhibition of fatty acid $\beta$-oxidation, ${ }^{31}$ increased TAG synthesis and lipid droplet formation may prevent the accumulation of toxic FFAs. Consistent with this proposal, we showed that inhibition of fatty acid synthesis with $\operatorname{TrC}$ increased FFA accumulation and enhanced cell death and that inhibition of FAO, with the CPT-I inhibitor etomoxir, enhanced lipid synthesis. In skeletal muscle cells, oleate has been shown recently to protect against palmitate-mediated lipotoxicity by channeling palmitate into TAG synthesis and by promoting palmitate oxidation ${ }^{37}$ and in pancreatic $\beta$-cells increased lipogenesis or $\beta$-oxidation were shown to protect against the toxicity associated with increased FFAs. ${ }^{38}$ There is also evidence that macrophages take advantage of lipid droplet accumulation as a mechanism to recognize and clear apoptotic cells, using the lipids from the engulfed apoptotic cell as peroxisome proliferator-activated receptor $\delta$ transcriptional activators that accelerate apoptotic cell removal and inhibit the inflammatory response. ${ }^{39}$

The lipid droplets have been shown to provide a signal for the non-invasive detection of tumor cell death post-treatment using ${ }^{1} \mathrm{H}$ magnetic resonance spectroscopy (MRS) techniques. ${ }^{13}$ The studies presented here have shown that droplet formation accompanies the very earliest events in the apoptotic program and therefore that these ${ }^{1} \mathrm{H}$ MRS measurements can potentially detect the very earliest signs of cell death.

\section{Materials and Methods}

Cell culture. HCT116, EL4, DU145 (ATCC, Teddington, UK) and C4-2b (ViroMed Laboratories, Minnetonka, MN, USA) cell lines were maintained using standard cell culture methods. HCT116 cells were grown in McCoy's 5A supplemented with $10 \%$ FBS, MEFs were grown in DMEM supplemented with $10 \% \mathrm{FBS}$ and all the other cell lines were grown in RPMI medium supplemented with $10 \%$ FBS. All cell culture reagents were obtained from Invitrogen (Paisley, UK). Cell number and viability were measured by the Trypan blue dye exclusion assay using a Vi-Cell counter (Beckman Coulter, High Wycombe, UK). Etoposide (Eposin) was obtained from PCH Pharmachemie (Haarlem, The Netherlands). DecylTPP and MitoQ were obtained from Dr. MP Murphy (Cambridge, UK). All other reagents were obtained from Sigma Aldrich (Gillingham, UK), unless specified otherwise.

Assessment of apoptosis and lipid droplet content. Cells $\left(5 \times 10^{6}\right)$ were centrifuged and resuspended in $1 \mathrm{ml}$ pre-warmed medium containing $100 \mathrm{nM}$ MTO CMTMRos (Invitrogen, Paisley, UK), incubated for $30 \mathrm{~min}$ at $37^{\circ} \mathrm{C}$ centrifuged and then resuspended in ice-cold $3 \%$ BSA in HBS (HEPES-buffered saline: $20 \mathrm{mM}$ HEPES, $150 \mathrm{mM} \mathrm{NaCl}, 2 \mathrm{mM} \mathrm{CaCl}_{2}$, pH 7.4) for $30 \mathrm{~min}$ at $4{ }^{\circ} \mathrm{C}$. After washing with HBS, cells were incubated in $100 \mu \mathrm{l} \mathrm{HBS}$ containing $5 \mu \mathrm{l} \mathrm{AV-Alexa}$ Fluor 647 (Invitrogen) for $30 \mathrm{~min}$ at room temperature. The resulting mixture was then washed three times with HBS and incubated for 20 min at room temperature with $1 \mathrm{ml} \mathrm{HBS}$ containing $10 \mathrm{ng} / \mathrm{ml}$ Bodipy 493/503 (Invitrogen). Finally, cells were washed twice with HBS and resuspended in $100 \mu \mathrm{l}$ ice-cold HBS containing $20 \mu \mathrm{g} / \mathrm{ml}$ of 7AAD (Invitrogen). Samples were kept on ice briefly before being loaded into an ImageStream flow cytometer system (Amnis Corporation, Seattle, WA, USA). For each sample, 10000 events were collected in standard mode. Data files were analyzed using the IDEAS software (Amnis Corporation) to gate the different populations according to their fluorescence staining, to acquire fluorescence images of individual cells and to measure the median intensity of the different dyes. Lipid droplet number (number of spots in the Bodipy $(500-560 \mathrm{~nm})$ channel) was obtained by applying the 'Spot Count' feature in the software, which compares the distribution of pixel intensities in an image, providing the number of continuously connected regions.

Measurement of lipid synthesis. At $1 \mathrm{~h}$ before cell harvest, $2 \mu \mathrm{Ci} / \mathrm{ml}$ $\left[1,2-{ }^{14} \mathrm{C}_{2}\right]$ acetate, $0.5 \mu \mathrm{Ci} / \mathrm{ml}\left[1-{ }^{14} \mathrm{C}\right]$ oleate (Perkin Elmer, Waltham, MA, USA) or $1 \mu \mathrm{Ci} / \mathrm{ml}\left[1-{ }^{14} \mathrm{C}\right]$ palmitate (GE Healthcare, Chalfont St Giles, UK) in $10 \% \mathrm{BSA}$ in PBS were added into the medium. Lipids were extracted from cell pellets by a modification of the Bligh and Dyer method ${ }^{40}$ and dissolved in an amount of chloroform proportional to the total cell number. Neutral lipids were resolved by thinlayer chromatography on a silica gel 60 plate (Whatman, Maidstone, UK) using a solvent system containing hexane: diethyl ether : acetic acid $(70: 30: 1)$, whereas for polar lipids the solvent system contained chloroform:methanol:acetic acid:water $(50: 37.5: 3.5: 2){ }^{18}$ Phosphor images were obtained using a Typhoon Trio System (GE Healthcare) and densitometric analysis of the different lipid bands was performed with the ImageQuant TL software (GE Healthcare).

Measurement of fatty acid $\beta$-oxidation. Cells were pretreated with $100 \mu \mathrm{M}$ oleate or palmitate dissolved in $10 \%$ BSA in PBS for $24 \mathrm{~h}$ before experiments; $0.5 \mu \mathrm{Ci} / \mathrm{ml}\left[1-{ }^{14} \mathrm{C}\right]$ oleate (Perkin Elmer) or $1 \mu \mathrm{Ci} / \mathrm{ml}\left[1-{ }^{14} \mathrm{C}\right]$ palmitate (GE Healthcare) was added to the culture medium $1 \mathrm{~h}$ before cell harvest. Trapping of ${ }^{14} \mathrm{CO}_{2}$ was performed as described in Fu et al. ${ }^{9}$ and counts determined using a liquid scintillation counter (Perkin Elmer). The measured radioactivity was normalized to cell number. To measure glucose oxidation, $2 \mu \mathrm{Ci} / \mathrm{ml} \quad \mathrm{D}$ $\left[\mathrm{U}-{ }^{14} \mathrm{C}\right.$ ]glucose (GE Healthcare) was added to the culture medium $1 \mathrm{~h}$ before cell harvest and the same procedure was used to measure ${ }^{14} \mathrm{CO}_{2}$ production.

Microscopy. For the microscopy experiments, 10000 cells were seeded into each well of a $\mu$-slide 8-well plate (Ibidi, Martinsried, Germany) in $300 \mu \mathrm{l}$ medium. Cells were fixed with $3 \%$ paraformaldehyde in PBS and then washed thoroughly with ice-cold PBS. Cells were stained with $0.3 \mu \mathrm{M} \mathrm{DAPI} \mathrm{(Invitrogen)} \mathrm{for} 5 \mathrm{~min}$ at room temperature, washed with ice-cold PBS and incubated for $30 \mathrm{~min}$ at room temperature with $1 \times$ HCS LipidTOX Deep Red neutral lipid stain (Invitrogen). Fluorescence images were acquired using a Nikon $\mathrm{C} 1 \mathrm{Si}$ confocal microscope (Nikon, Kingston, UK).

Real-time quantitative reverse transcription-PCR. RNA was extracted by using the RNeasy Plus Mini kit (Qiagen, Crawley, UK) and reverse transcription performed using the SuperScript III First-Strand Synthesis System for RT-PCR (Invitrogen). The sequences of the forward (fw) and reverse (rev) primers used for amplification were as follows: ACLY, $5^{\prime}$-GGGTGACTCCCGACACAGAC T-3' (fw) and $5^{\prime}$-TGATTAACTGGTCTGGCTTGACA-3' (rev); ACC1, $5^{\prime}$-CAGTCTAC ATCCGCTTGGCTG-3' (fw) and 5'-CAGCTCCTTCCGCTCAGTG-3' (rev); FASN, $5^{\prime}$-TCCTGGAACGAGAACACGATCT-3' (fw) and 5'-GAGACGTGTCACTCCTGGA CTTG-3' (rev); p21, 5'-GACAAGAGGCCCAGTACTTCCT-3' (fw) and $5^{\prime}$-CAATCTG CGCTTGGAGTGATA-3' (rev); Sestrin2, 5'-CTCACAGCTGGTCTGTGTG-3' (fw) and $5^{\prime}$-CCTCCGTGTGGCAATACC-3' (rev); actin, 5'-CTTCAACACCCCAGCCAT GTA-3' (fW) and 5'-CATCACAATGCCTGTGGTACG-3' (rev); L32, 5'-AAGCGAAA CTGGCGGAAAC-3' (fw) and 5'-GATCTGGCCCTTGAACCTTCT-3' (rev).

The actin gene was used as an internal control to normalize the results of the real-time reverse transcription-PCR. Power SYBR Green PCR Master Mix (Applied Biosystems, Carlsbad, CA, USA) was used to setup the reactions. Amplification and detection were performed on a $7900 \mathrm{HT}$ Fast Real-Time PCR System (Applied Biosystems) using the following cycling conditions: $50^{\circ} \mathrm{C}$ for $2 \mathrm{~min}, 95^{\circ} \mathrm{C}$ for $10 \mathrm{~min}$, followed by 40 cycles of $95^{\circ} \mathrm{C}$ for $15 \mathrm{~s}$ and $60^{\circ} \mathrm{C}$ for $1 \mathrm{~min}$. A dissociation stage of $95^{\circ} \mathrm{C}$ for $15 \mathrm{~s}$ and $60^{\circ} \mathrm{C}$ for $15 \mathrm{~s}$ was added to check reaction specificity. The $\mathrm{Ct}$ values obtained were converted to relative expression values by the comparative $\mathrm{Ct}$ method, correcting with the values obtained for actin and normalizing to the untreated control levels.

Western blots. Cell pellets were washed with ice-cold PBS and stored at $-80^{\circ} \mathrm{C}$ until use. Pellets were solubilized in M-PER Mammalian Protein Extraction Reagent (Thermo Scientific, Cramlington, UK) supplemented with PhosSTOP Phosphatase Inhibitor Cocktail (Roche Applied Science, Burgess Hill, UK) and COMPLETE-mini Protease Inhibitor Cocktail (Roche Applied Science) and sonicated for $5 \mathrm{~min}$. Cell debris was removed by centrifugation. Protein concentrations were determined using QuickStart Bradford Assay (Bio-Rad, Hemel Hempstead, UK). In all, $20 \mu \mathrm{g}$ of protein were loaded into each channel on a 4-20\% gel and transferred on to polyvinylidene fluoride membranes (Invitrogen). Membranes were probed with the following antibodies: p53, Akt, phospho-Akt 
(Ser473), phospho-p70 S6 kinase (Ser371), phospho-p70 S6 kinase (Thr389), AMPK, phospho-AMPK (Thr172), ATP-citrate lyase, phospho-ATP-citrate lyase (Ser454), acetyl-CoA carboxylase, phospho-acetyl-CoA carboxylase (Ser79), FASN, acetyl-CoA synthetase, SirT1, caspase 3, cleaved caspase 3 (all from Cell Signaling Technology, Danvers, MA, USA), FSP27 (Abcam, Cambridge, UK) and actin (Sigma Aldrich). Densitometric analysis was performed with the ImageQuant TL software (GE Healthcare).

$\mathrm{NAD}^{+}$/NADH measurement. Levels of $\mathrm{NAD}^{+}$and NADH were measured using an $\mathrm{NAD}^{+} / \mathrm{NADH}$ quantification kit (BioVision, Mountain View, $\mathrm{CA}, \mathrm{USA}$ ), according to the manufacturer's instructions.

ROS measurement. At $1 \mathrm{~h}$ before cell collection, $100 \mu \mathrm{M}$ carboxy- $\mathrm{H}_{2}$ DCFDA (Invitrogen) was added to each cell sample, with the cells maintained in an incubator $\left(37^{\circ} \mathrm{C}, 5 \% \mathrm{CO}_{2}\right)$. After incubation, the cells were washed with ice-cold $\mathrm{HBS}$ and resuspended in $1 \mathrm{ml} \mathrm{HBS}$. A total of 20000 cells were analyzed for each sample in an LSRII flow cytometer (BD Biosciences, Oxford, UK) and the median intensity of the dye was measured.

Statistical analysis. Values are expressed as mean \pm S.E.M., unless specified otherwise. Significant differences between mean values were determined by applying the unpaired Student's two-tailed $t$-test. Differences between groups were considered significant if $P<0.05$.

\section{Conflict of Interest}

The authors declare no conflict of interest.

Acknowledgements. JB was supported by a Marie Curie Intra European Fellowship within the 7th European Community Framework Programme. This work was supported by a Cancer Research UK Programme Grant to KMB (C197/A3514). We thank the Equipment Park, Microscopy and Flow Cytometry facilities from the Cambridge Research Institute for their assistance; Dr. Mike P. Murphy for providing MitoQ reagent and Dr. Pedro Perez-Mancera for providing the MEFs.

1. Buchakjian MR, Kornbluth $\mathrm{S}$. The engine driving the ship: metabolic steering of cell proliferation and death. Nat Rev Mol Cell Biol 2010; 11: 715-727.

2. Engelman JA, Luo J, Cantley LC. The evolution of phosphatidylinositol 3-kinases as regulators of growth and metabolism. Nat Rev Genet 2006; 7: 606-619.

3. Bensaad K, Tsuruta A, Selak MA, Vidal MNC, Nakano K, Bartrons R et al. TIGAR, a p53inducible regulator of glycolysis and apoptosis. Cell 2006; 126: 107-120.

4. Hu W, Zhang C, Wu R, Sun Y, Levine A, Feng Z. Glutaminase 2, a novel p53 target gene regulating energy metabolism and antioxidant function. Proc Natl Acad Sci 2010; 107: 7455-7460.

5. Vousden KH, Prives C. Blinded by the light: the growing complexity of p53. Cell 2009; 137: 413-431.

6. Feng Z, Levine AJ. The regulation of energy metabolism and the IGF- $1 / \mathrm{mTOR}$ pathways by the p53 protein. Trends Cell Biol 2010; 20: 427-434.

7. Hardie DG. The AMP-activated protein kinase pathway - new players upstream and downstream. J Cell Sci 2004; 117: 5479-5487.

8. Budanov AV, Karin M. P53 target genes Sestrin1 and Sestrin2 connect genotoxic stress and mTOR signaling. Cell 2008; 134: 451-460.

9. Fu X, Wan S, Lyu YL, Liu LF, Qi H. Etoposide induces ATM-dependent mitochondrial biogenesis through AMPK activation. PLOS One 2008; 3: e2009.

10. Porstmann T, Santos $C R$, Griffiths B, Cully M, Wu M, Leevers $S$ et al. SREBP activity is regulated by mTORC1 and contributes to Akt-dependent cell growth. Cell Metab 2008; 8: 224-236.

11. Gwinn DM, Shackelford DB, Egan DF, Mihaylova MM, Mery A, Vasquez DS et al. AMPK phosphorylation of Raptor mediates a metabolic checkpoint. Mol Cell 2008; 30: 214-226.

12. Ruderman NB, Saha AK, Kraegen EW. Minireview: malonyl CoA, AMP-activated protein kinase, and adiposity. Endocrinology 2003; 144: 5166-5171.

13. Blankenberg FG. In vivo detection of apoptosis. J Nucl Med 2008; 49: 81S-895.

14. Callies R, Sri-Pathmanathan RM, Ferguson DY, Brindle KM. The appearance of neutral lipid signals in the ${ }^{1} \mathrm{H}$ NMR spectra of a myeloma cell line correlates with the induced formation of cytoplasmic lipid droplets. Magnet Resonan Med 1993; 29: 546-550.

15. Hakumaki JM, Kauppinen RA. ${ }^{1} \mathrm{H}$ NMR visible lipids in the life and death of cells. Trends Biochem Sci 2000; 25: 357-362.
16. Hakumaki JM, Poptani H, Sandmair A-M, Yla-Herttuala S, Kauppinen RA. ${ }^{1} \mathrm{H}$ MRS detects polyunsaturated fatty acid accumulation during gene therapy of glioma: implications for the in vivo detection of apoptosis. Nat Med 1999; 5: 1323-1327.

17. Quintero $M$, Cabañas $M E$, Arús $C .{ }^{13} \mathrm{C}$-labelling studies indicate compartmentalized synthesis of triacylglycerols in C6 rat glioma cells. Biochim Biophys Acta 2010; 1801: 693-701.

18. Iorio E, Di Vito M, Spadaro F, Ramoni C, Lococo E, Carnevale R et al. Triacsin C inhibits the formation of $1 \mathrm{H}$ NMR-visible mobile lipids and lipid bodies in HuT 78 apoptotic cells. Biochim Biophys Acta 2003; 1634: 1-14.

19. Delikatny EJ, Cooper WA, Brammah S, Sathasivam N, Rideout DC. Nuclear magnetic resonance-visible lipids induced by cationic lipophilic chemotherapeutic agents are accompanied by increased lipid droplet formation and damaged mitochondria. Cancer Res 2002; 62: 1394-1400.

20. Guo Y, Cordes KR, Farese Jr RV, Walther TC. Lipid droplets at a glance. J Cell Sci 2009; 122: $749-752$.

21. Farese RV, Walther TC. Lipid droplets finally get a little R-E-S-P-E-C-T. Cell 2009; 139: $855-860$.

22. Keller P, Petrie JT, De Rose P, Gerin I, Wright WS, Chiang S-H et al. Fat-specific protein 27 regulates storage of triacylglycerol. J Biol Chem 2008; 283: 14355-14365.

23. Keij JF, Bell-Prince C, Steinkamp JA. Staining of mitochondrial membranes with 10-nonyl acridine orange MitoFluor Green, and MitoTracker Green is affected by mitochondrial membrane potential altering drugs. Cytometry 2000; 39: 203-210.

24. Scaduto RC, Grotyohann LW. Measurement of mitochondrial membrane potential using fluorescent rhodamine derivatives. Biophys J 1999; 76: 469-477.

25. Anthony ML, Zhao M, Brindle KM. Inhibition of phosphatidylcholine biosynthesis following induction of apoptosis in HL-60 cells. J Biol Chem 1999; 274: 19686-19692.

26. Mashima T, Sato S, Okabe S, Miyata S, Matsuura M, Sugimoto $Y$ et al. Acyl-CoA synthetase as a cancer survival factor: its inhibition enhances the efficacy of etoposide. Cancer Sci 2009; 100: 1556-1562.

27. Hallows WC, Lee S, Denu JM. Sirtuins deacetylate and activate mammalian acetyl-CoA synthetases. Proc Natl Acad Sci USA 2006; 103: 10230-10235.

28. Witney TH, Kettunen MI, Day SE, Hu DE, Neves AA, Gallagher FA et al. A comparison between radiolabeled fluorodeoxyglucose uptake and hyperpolarized (13)C-labeled pyruvate utilization as methods for detecting tumor response to treatment. Neoplasia 2009; 11: 574-582.

29. Agius L, Meredith EJ, Sherratt HSA. Stereospecificity of the inhibition by etomoxir of fatty acid and cholesterol synthesis in isolated rat hepatocytes. Biochem Pharmacol 1991; 42 1717-1720.

30. Liu K, Zhou S, Kim J-Y, Tillison K, Majors D, Rearick D et al. Functional analysis of FSP27 protein regions for lipid droplet localization, caspase-dependent apoptosis, and dimerization with CIDEA. Am J Physiol Endocrinol Metab 2009; 297: E1395-E1413.

31. Schafer ZT, Grassian AR, Song L, Jiang Z, Gerhart-Hines Z, Irie HY et al. Antioxidant and oncogene rescue of metabolic defects caused by loss of matrix attachment. Nature 2009; 461: 109-113.

32. Skulachev V. Bioenergetic aspects of apoptosis, necrosis and mitoptosis. Apoptosis 2006; 11: 473-485.

33. Kelso GF, Porteous CM, Coulter CV, Hughes G, Porteous WK, Ledgerwood EC et al. Selective targeting of a redox-active ubiquinone to mitochondria within cells. J Biol Chem 2001; 276: 4588-4596.

34. Smith RAJ, Porteous CM, Coulter CV, Murphy MP. Selective targeting of an antioxidant to mitochondria. Eur J Biochem 1999; 263: 709-716.

35. Korge P, Weiss $\mathbf{J N}$. Redox regulation of endogenous substrate oxidation by cardiac mitochondria. Am J Physiol Heart Circ Physiol 2006; 291: H1436-H1445.

36. Hurd TR, Prime TA, Harbour ME, Lilley KS, Murphy MP. Detection of reactive oxygen species-sensitive thiol proteins by redox difference gel electrophoresis. J Biol Chem 2007; 282: 22040-22051.

37. Henique C, Mansouri A, Fumey G, Lenoir V, Girard J, Bouillaud F et al. Increased mitochondrial fatty acid oxidation is sufficient to protect skeletal muscle cells from palmitate-induced apoptosis. J Biol Chem 2010; 285: 36818-36827.

38. Choi S-E, Jung I-R, Lee Y-J, Lee S-J, Lee J-H, Kim Y et al. Stimulation of lipogenesis as well as fatty acid oxidation protects against palmitate-induced INS-1 beta-cell death Endocrinology 2011; 152: 816-827.

39. Mukundan L, Odegaard JI, Morel CR, Heredia JE, Mwangi JW, Ricardo-Gonzalez RR et al. PPAR-[delta] senses and orchestrates clearance of apoptotic cells to promote tolerance. Nat Med 2009; 15: 1266-1272.

40. Hatzivassiliou G, Zhao F, Bauer DE, Andreadis C, Shaw AN, Dhanak D et al. ATP citrate lyase inhibition can suppress tumor cell growth. Cancer Cell 2005; 8: 311-321.

This work is licensed under the Creative Commons SOMERRIHISRRESERVED Attribution-NonCommercial-No Derivative Works 3.0
Unported License. To view a copy of this license, visit http:/l creativecommons.org/licenses/by-nc-nd/3.0

\section{Supplementary Information accompanies the paper on Cell Death and Differentiation website (http://www.nature.com/cdd)}

